\title{
Experiments on supercritical flow instability in two vertical parallel channels
}

\author{
Inderjit Singh ${ }^{1}$, Vijay Chatoorgoon ${ }^{2}$ \\ ${ }^{1}$ University of Manitoba \\ 18 Kenneth street, Winnipeg, Canada \\ Singhi2@myumanitoba.ca ; Vijay.chatoorgoon@umanitoba.ca \\ ${ }^{2}$ University of Manitoba \\ E1-408 75A Chancellor Circle ca, Winnipeg, Canada
}

\begin{abstract}
Very limited experimental data on supercritical flow instability is present in the literature. To enrich this limited database and to further the understanding of supercritical flow instability, an experimental study was conducted using two vertical parallel channels with supercritical $\mathrm{CO}_{2}$. A total of 7 experimental cases were performed with a system pressure range of $8.25-9.1 \mathrm{MPa}$ and inlet temperatures $0.5-10.05{ }^{\circ} \mathrm{C}$. The channel inlet temperature and system pressure were held constant and the input power was increased gradually until mass flow oscillations commenced. The distribution of mass flow rate in the channels with input power increase was examined. Initially, at low input power, the flow rate in the channels was almost equal, with an increase in input power, it got distributed in channels and become asymmetric, and with the further input power increase, it started oscillating $180{ }^{\circ}$ out-of-phase. The results for seven experimental cases are presented and these would be useful for code validation purposes.
\end{abstract}

Keywords: Parallel channel super-critical flow instability, SCWR (super-critical water reactor), Supercritical $\mathrm{CO}_{2}$, Thermal hydraulic instability.

\section{Introduction}

The fluid near the critical point is considered as an efficient source of heat transfer medium due to its high specific heat and large coefficient of thermal expansion. Demand for increased system efficiency has generated interest in using supercritical fluid as the working media. The Super-critical water reactor (SCWR) is one of the promising generations IV advanced reactor design that uses supercritical light water as a coolant. The water enters the core at a pressure of $25 \mathrm{MPa}$ with a temperature of around $280{ }^{\circ} \mathrm{C}$ and leaves at a temperature beyond $500{ }^{\circ} \mathrm{C}$. Because of the high operating temperature, the efficiency of SCWR can approach $\sim 44 \%$ compared to $\sim 33-36 \%$ for generation III reactor designs. Besides this, its size is compact due to the elimination of steam dryers, steam generators, and steam separators. This is because supercritical fluid exists in the single-homogenous state i.e., no boiling phenomena occur for supercritical fluids. However, despite having these advantages, the SCWR faces problems related to mass flow instability, heat transfer, material chemistry and safety features and is, therefore, still in the developmental phase.

Mass flow instability at supercritical conditions is discussed in this paper. This problem is not only limited to the SCWR, but it can occur in other engineering systems under certain supercritical conditions, like nuclear rocket engines and micro-channels used in electronic devices. Generally, two types of mass flow instabilities have been reported at supercritical conditions. The first is the static or Ledinegg instability and the second is the dynamic instability. In the static or Ledinegg instability, mass flow rate changes its original steady-state to a new steady-state, whereas in dynamic instability, the mass flow rate oscillates in a diverging manner. Whether static or dynamic, mass flow instability is highly undesirable because the mechanical vibrations and thermal fatigue caused by these oscillations may result in structural damage. Therefore, for the safe working of an engineering system, it is necessary to determine the conditions leading to the commencement of mass flow oscillations so the system can operate away from those conditions. 


\section{Relevant Work}

Zuber[1] reported early theoretical work on supercritical flow instability for a single channel. The governing equations were linearized by applying a small perturbation to the inlet flow, and the linear equations were integrated along the channel to produce a characteristic equation and flow instability was studied. Zhao et al.[2] proposed a three-region model for supercritical flow and examined supercritical flow instability in a single channel. The finding was that flow stability increases with increasing the channel inlet pressure drop coefficient. Ambrosini et al.[3] showed the occurrence of static instability at low temperatures for a single channel. Chatoorgoon [4] also showed the existence of static instability at low temperatures for two identical parallel channels and demonstrated that down-flow was highly susceptible to static instability, followed by horizontal and up-flow. Su et al. [5] stated that flow stability for two vertical up-flow parallel channels increases with an increase in inlet pressure drop, system pressure, and decreasing channel diameter. Xiong et al.[6] performed nine supercritical water experiments with two vertical parallel channels. The findings were that the system stability increases with the system pressure increase. The system stability decreased with inlet temperature increase. However, the inflection point for temperature increase was not reached because of the temperature limit of the experimental facility. Xi et al. [7] also conducted an experimental study on Xiong et al.[6] experimental facility, but used a thicker pipe wall. Five uniform and seven non-uniform power profile experiments were performed. However, the nonuniform power profile cases were unrealistically large step for a nuclear reactor, as in nuclear reactor the power variation is gradual, not a sudden large step. Shisti et al.[8] modeled the experiments of Xi et al.[7] using CFD software, STAR$\mathrm{CCM}+$. The obtained numerical results showed good agreement with the experimental data. Moreover, the study concluded that the flow stability boundary of the system increases with system pressure increase. Saini et al. [9] conducted an up-flow experimental study with two vertical parallel channels using supercritical $\mathrm{CO}_{2}$. Experiments were performed using wide range of system parameters.

Debrah et al.[10] and Sharma et al.[11] used a 1-D non-linear program to examine the effect of thermal wall storage on the flow stability boundary using a natural circulation loop. They reported that the flow stability of the system increases largely when modeled with the thermal wall storage. Liu et al.[12] reported a similar finding for a single vertical up-flow channel. The effect of pipe length on flow stability boundary was also examined. Ghadge et al. [13] showed that the inclusion of the thermal wall storage makes a large effect on flow stability boundary for a single vertical up-flow channel. However, there was a small effect for two dissimilar vertical up-flow parallel channels and no effect for two identical vertical up-flow parallel channels. The experiments performed by Xiong et al.[6] and Xi et al.[7] were modeled using a 1$\mathrm{D}$ linear in-house program. They reported that the prediction of the threshold power and the period of oscillation improved with the inclusion of thermal wall storage.

\section{Study Objective}

It is apparent from the literature that the experimental work for parallel channel supercritical flow instability is sparse and insufficient. Therefore, the main objective of the study was to enrich the limited database by performing instability experiments using supercritical $\mathrm{CO}_{2}$ in two vertical up-flow parallel channels. The experimental instability data would be useful for those who wish to validate the licensed software's or in-house programs. Validating codes with experimental data can further the understanding of supercritical flow instability in various geometries and configurations, making codes sufficiently accurate for engineering use.

\section{Experimental Setup}

The experimental setup consists mainly of the following systems:
A. The test section
B. The cooling system
C. The evacuation system
D. The power supply system 


\section{E. The data acquisition system}

F. The safety system

The test section consists of two vertical parallel channels made up of INCONEL 825. The reason for using INCONEL 825 was to ensure a uniform distribution of heat flux as INCONEL has a minimal change in resistance to temperature changes. Each channel consists of vertical and horizontal entry section, flow meter, inlet and outlet valves, and riser section. Both channels were connected to a common lower and common upper plenum. A flow meter was installed on the horizontal entry section, and ball valves were installed at the inlet and the outlet of each channel. A uniform power was applied axially to the channels and incremented in small steps. However, a small power difference was established naturally between the channels, which was beyond our control. The whole loop was insulated with the Superwool fiber to reduce the heat loss to the surroundings. Fig. 1 shows a schematic diagram of the test section. The cooling system removes the heat from the working fluid coming out of the test section. It mainly consists of two heat exchangers, coolant pump, flow meter, sump, and valves. The coolant used was propylene glycol solution. The evacuation system consists of a vacuum pump and needle valves. The loop was first evacuated to ensure the purity of the working fluid $\left(\mathrm{CO}_{2}\right)$, then flooded with $\mathrm{CO}_{2}$. It was done before filling the loop with $\mathrm{CO}_{2}$ so that there are negligible contaminants in the loop. The power supply system consists of a 30-kW rectifier that supplies DC power to the test section channels. The channels get heated up because of the electrical resistance of the INCONEL 825 material. A high accuracy data acquisition system was used to record real-time conditions such as temperature, volume flow rate, pressure, pressure drop, and heating power. The experimental facility consists of various safety systems like pressure relief valves, perplex containment, lock-key switch, limit switch, and emergency stop button to ensure the safety of the operator and system.
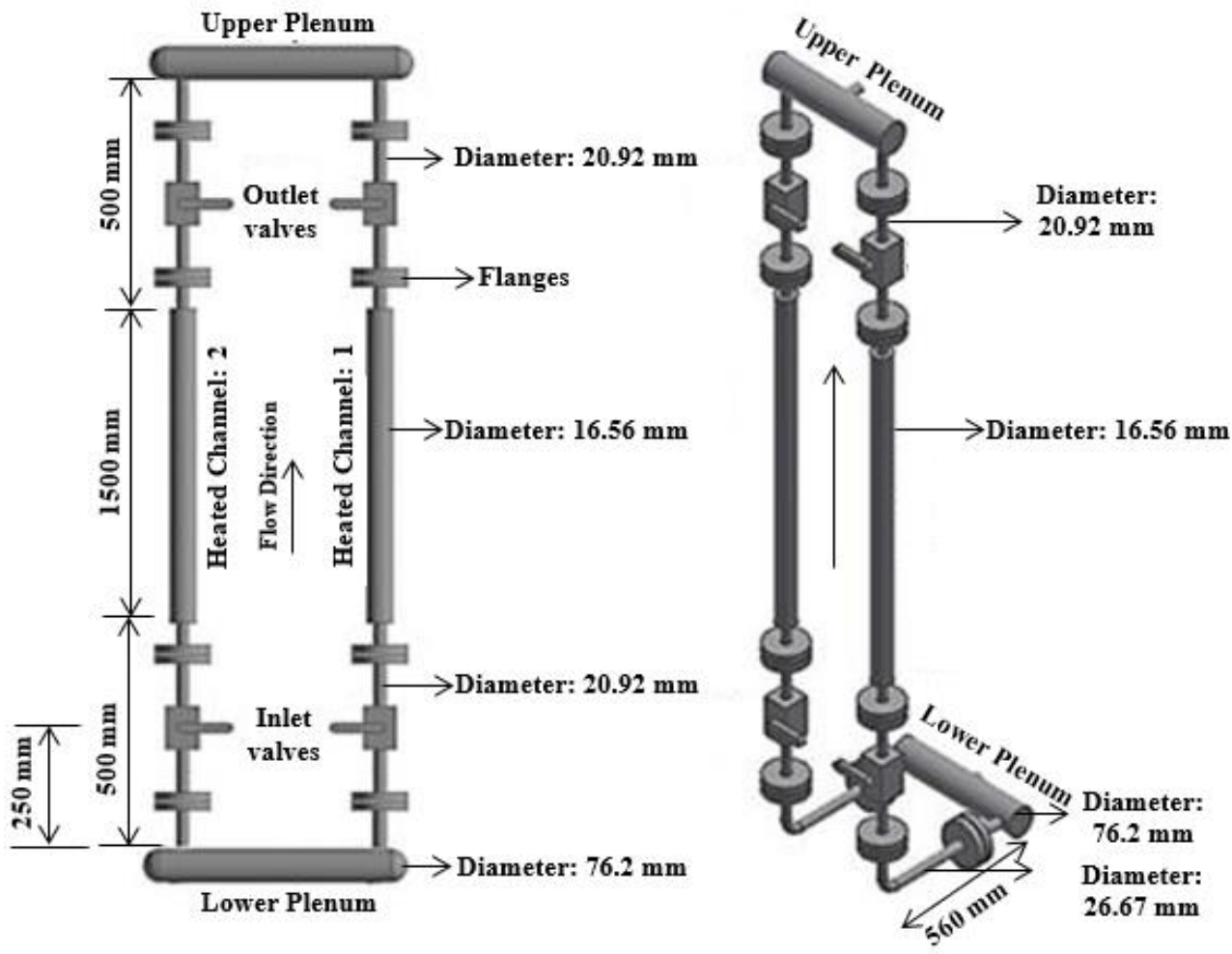

Fig. 1: Schematic diagram of the test section.

The main flow was driven by natural convection forces as money for a pump was not available. However, natural circulation was not a factor in the channel instability as we ensured the main flow to the inlet header was steady in all 
cases. The working fluid used in experiments was $\mathrm{CO}_{2} \cdot \mathrm{CO}_{2}$ was chosen over water because of the low critical point. The critical pressure and temperature of $\mathrm{CO}_{2}$ is $7.37 \mathrm{MPa}$ and $31{ }^{\circ} \mathrm{C}$, whereas for water it is $22.064 \mathrm{MPa}$ and $374{ }^{\circ} \mathrm{C}$.

\section{Measurement Instruments}

Various instruments were used in the experiment to measure the real-time mass flow rate, system pressure, pressuredrop, electrical power, and temperature. T-types thermocouples were used to measure the fluid temperature and K-types thermocouples were used to measure the wall temperature of the test section channels. The temperature range of the T-type thermocouple is -200 to $+350{ }^{\circ} \mathrm{C}$ and that of the $\mathrm{K}$-type thermocouple is -200 to $+1350{ }^{\circ} \mathrm{C}$. A turbine flow meter was installed at the inlet of each channel to measure the mass flow rate. The flow meter range is 0.6 40 GPM (Gallons per minute). Differential pressure transducers (DP cells) were used to measure the pressure drop across the valves, heat exchanger, and heated sections. An absolute differential transducer was used to measure the system pressure. In addition, pressure gauge was also used to measure the system pressure. The range of the differential pressure transducer was $0 \sim 8$ psi and the absolute differential transducer and the pressure gauge were $0 \sim 1500 \mathrm{psi}$. An isolated DC voltmeter was used to measure the voltage drop across each channel. Table 1 summarizes the details of uncertainties in the measuring instruments. The uncertainties in measurement were evaluated from the accuracy of the instruments and calibration of the sensors.

Table 1. Uncertainties in measurement.

\begin{tabular}{|l|l|}
\hline Parameter & Uncertai \\
nty
\end{tabular}

\section{Test preparation and test procedure}

Prior to performing the experiments, a preparation test was done. It mainly consisted of calibrating the DP cells, performing the leakage test, vacuuming the loop, and adjusting the position of the valves. After preparing the loop, the following procedure was followed to perform the experiment:

a) Initially, the loop was directly charged with $\mathrm{CO}_{2}$ cylinder, which supplied pressure up to $5.8 \mathrm{MPa}$. Since this pressure is far below the supercritical pressure, a booster pump was used to raise the system pressure to the supercritical pressure.

b) After this, all doors of the perplex containment were locked, and the lock-key switch was turned ON.

c) The rectifier, rooftop chiller, and coolant pump were turned ON.

d) $0.5 \mathrm{~kW}$ power was applied to the test section. The power was increased with an increment of $0.5 \mathrm{~kW}$ in approximately five minutes. A constant inlet temperature was maintained by adjusting the coolant mass flow rate.

e) The desired pressure was achieved by increasing the applied power. If the desired pressure was exceeded, any excess pressure was released to the atmosphere by opening the outlet needle valve. (Accumulator was not used for this purpose).

f) When the desired inlet temperature and system pressure were achieved, and the flow was steady, and data was recorded for 5 minutes to record the initial conditions. 
g) The recording was stopped, and power was further increased gradually until out-of-phase self-sustained mass flow oscillations were noted.

h) Once out-of-phase self-sustained mass flow oscillations were observed, the power was reduced to $1 \mathrm{~kW}$ to suppress the oscillations and record data. Now, power was increased at a more gradual rate, $0.2 \mathrm{~kW}$ in every five minutes to record data in search of the flow instability boundary.

\section{Results and discussions}

A total of seven instability boundary experiments were performed. In all the cases, oscillatory flow instability (dynamic flow instability) was observed. The results are discussed in the following sections:

\subsection{Determination of mass flow instability boundary}

Determining the correct instability boundary is of utmost importance as any deviation away from the actual instability boundary will give an inaccurate prediction of results. Xiong et al. [6] and Saini et al. [9] in their experimental work had disregarded small life transient oscillations and considered only self-sustained mass flow oscillations with evident amplitude, for the flow instability boundary prediction. Shisti et al. [14] recommended that for the system to be unstable, the amplitude of mass flow oscillations should to be greater than $\pm 10 \%$.

In current experimental cases, the channel inlet temperature, system pressure, inlet and outlet channel valve openings were fixed. Only the input power was increased in small steps. Therefore, the input power was the only parameter that affects the stability of the flow. Here, the flow instability boundary was determined when self-sustained out-of-phase mass flow oscillations with evident amplitude appeared with the input power increment. Fig. 4 shows the commencement of self-sustained mass flow oscillations with evident amplitude $( \pm 15 \%)$ with input power increment. In all the cases, the amplitude value for mass flow oscillations was greater than $\pm 10 \%$. The power corresponding to mass flow oscillations with evident amplitude was the threshold power for the system. It was predicted for all seven experimental cases.

Table 2 presents the average data of $30 \mathrm{sec}$ of the system parameters before the onset of out-of-phase mass flow oscillations with evident amplitude. This data would be useful for those who wish to validate the licensed software's or inhouse programs. The inlet $K$-factors for all seven cases for channel 1 and channel 2 were 1.2 and 1.3, respectively.

Table 2. Parameters at the onset of the mass flow oscillations: [ Fluid: $\mathrm{CO}_{2}$ ].

\begin{tabular}{|c|c|c|c|c|c|c|c|c|c|c|c|}
\hline CASE & & WER [kW & & Mass $\mathrm{F}$ & ow Rate [ & $\left.\mathrm{g} \mathrm{s}^{-1}\right]$ & $\begin{array}{l}\text { Inlet } \\
\text { Temp. }\end{array}$ & $\begin{array}{l}\text { System } \\
\text { Pressure }\end{array}$ & $\begin{array}{r}\text { Outlet } \\
\text { fo }\end{array}$ & $\begin{array}{l}\text { alve } K \text { - } \\
\text { or }\end{array}$ & $\begin{array}{c}\text { Oscillation } \\
\text { period }\end{array}$ \\
\hline No. & $\begin{array}{c}\text { Channel } \\
1\end{array}$ & $\begin{array}{c}\text { Channel } \\
2\end{array}$ & Total & $\begin{array}{c}\text { Channel } \\
1\end{array}$ & $\begin{array}{c}\text { Channel } \\
2\end{array}$ & Total & {$\left[{ }^{\circ} \mathrm{C}\right]$} & $\mathrm{MPa}$ & $\begin{array}{c}\text { Channel } \\
1\end{array}$ & $\begin{array}{c}\text { Channel } \\
2\end{array}$ & Second [s] \\
\hline 1. & 8.74 & 8.46 & 17.20 & 0.04476 & 0.03370 & 0.07846 & 6.60 & 9.09 & 3.2 & 23.8 & 7.80 \\
\hline 2. & 8.25 & 7.98 & 16.23 & 0.04160 & 0.03445 & 0.07605 & 1.90 & 8.74 & 3.2 & 23.8 & 7.19 \\
\hline 3. & 8.65 & 8.37 & 17.02 & 0.04253 & 0.03471 & 0.07724 & 3.50 & 8.97 & 3.2 & 23.8 & 7.20 \\
\hline 4. & 8.87 & 8.58 & 17.45 & 0.04286 & 0.03549 & 0.07835 & 4.60 & 8.55 & 3.2 & 23.8 & 6.60 \\
\hline 5. & 8.70 & 8.40 & 17.10 & 0.04260 & 0.03560 & 0.07822 & 5.50 & 8.3 & 3.2 & 23.8 & 6.07 \\
\hline 6. & 8.80 & 8.50 & 17.30 & 0.042168 & 0.03442 & 0.07661 & 0.54 & 9.054 & 3.2 & 23.8 & 7.19 \\
\hline
\end{tabular}




\begin{tabular}{|l|l|l|l|l|l|l|l|l|l|l|l|}
\hline 7. & 7.90 & 7.60 & 15.50 & 0.03090 & 0.04495 & 0.07585 & 10.05 & 8.25 & 23.8 & 3.2 & 6.10 \\
\hline
\end{tabular}

\subsection{Mass flow rate distribution in channels}

Figs. 2-5 show the channel distribution of mass flow rates. The power shown in Figs. $2-5$ is the electrical power to each channel; the mass flow rate is in liters per minute.

a) Initially, at low input power, the mass flow rate between the channels was almost equal (Fig. 2). Here, the channel outlet fluid temperature for both the channels was below the pseudo-critical point.

b) With an increase in input power, the mass flow rate distributed unevenly between the channels, and becomes asymmetric (Fig. 3). Here, the channel outlet fluid temperature for both the channels was in the vicinity of the pseudo-critical point.

c) With further increase in input power, the mass flow rates started oscillating $180^{\circ}$ out-of-phase, and flow instability boundary was determined (Figs. $4 \& 5$ ). Here, the channel outlet fluid temperature for both the channels was beyond the pseudo-critical point.

A similar type of mass flow distribution in channels was also reported for water[6].

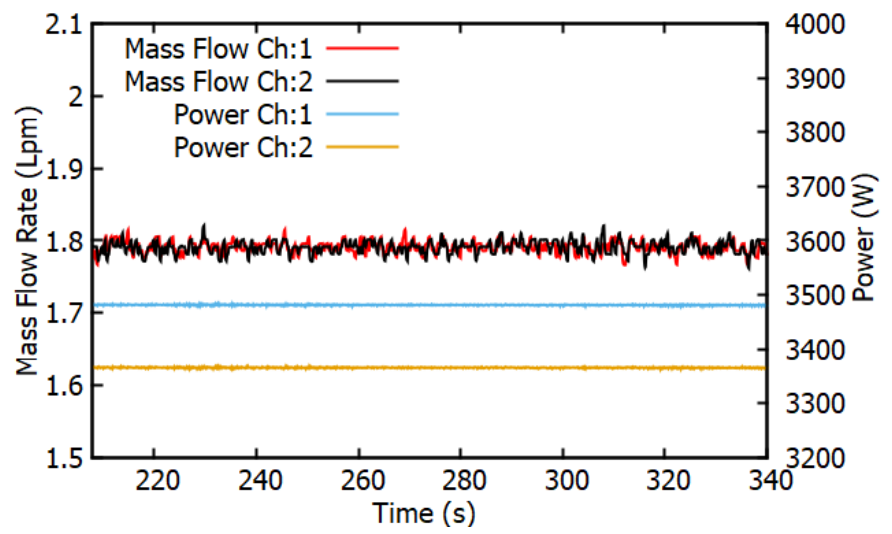

Fig. 2. Almost symmetrical mass flow rate between the channels (case 1).

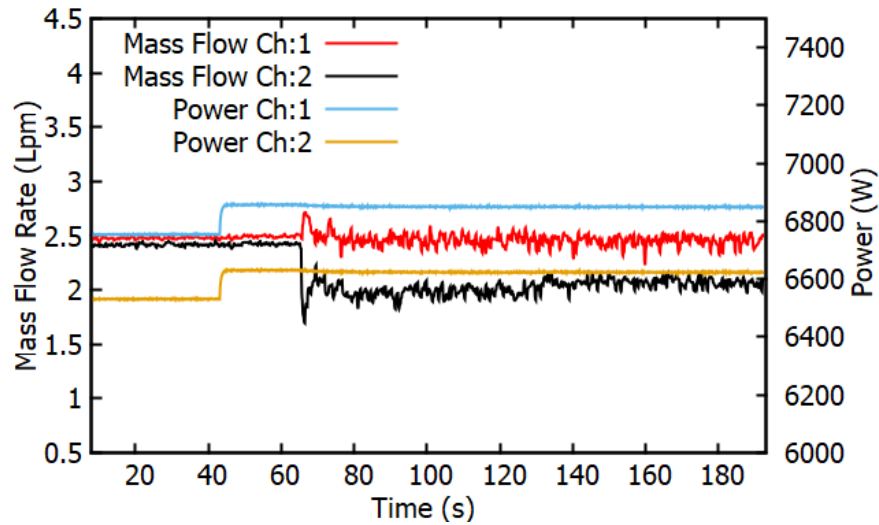

Fig. 3. Distribution of mass flow rate between the channels with input power increase (case 1).

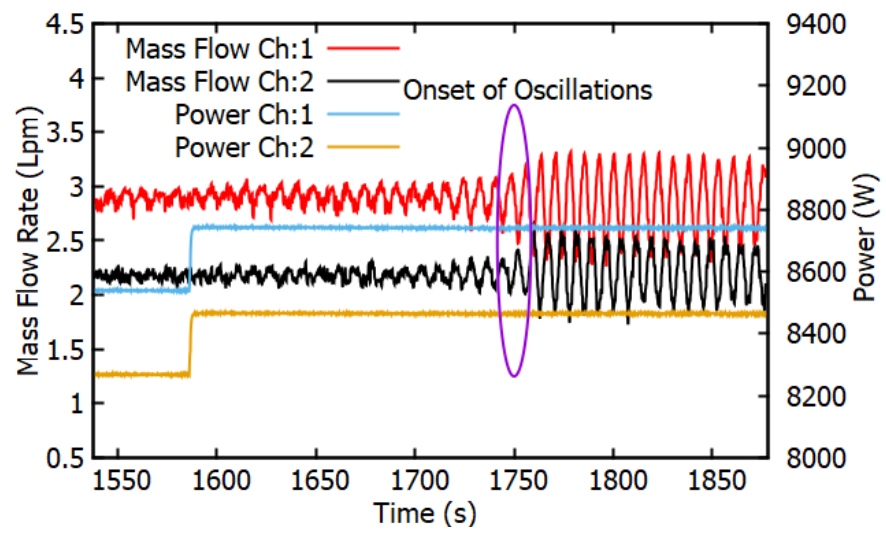

Fig. 4. The onset of the mass flow oscillations (case1).

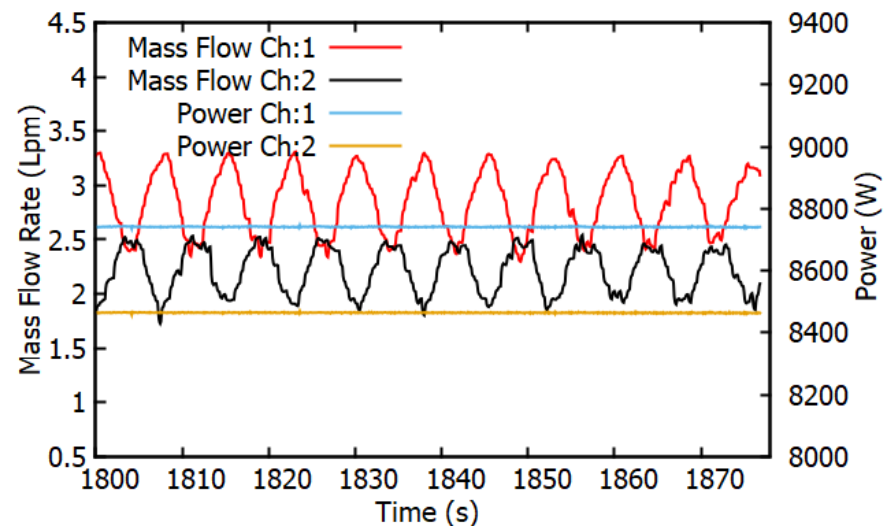

Fig. 5. Mass flow oscillations at flow instability boundary (case 1). 


\subsection{Estimating uncertainty in predicting flow instability boundary}

In an experiment, the channel flow instability boundary is governed by the inlet and outlet channel $K$-factors, system pressure, inlet temperature, and mass flow rate. If the channel inlet $K$-factor is increased, the stability boundary gets increased, and if the channel outlet $K$-factor is increased, the stability boundary gets decreased. With an increase in system pressure and channel mass flow rate, stability boundary increases. With an increase in channel inlet temperature, the stability boundary decreases up to a certain point, and thereafter it starts increasing. Since $K$-factors, system pressure, inlet temperature, and mass flow rate have a direct impact on the channel flow instability boundary; therefore, uncertainty in flow instability boundary comprises of the combination of uncertainties related to these parameters.

When calculating quantities with uncertainties, the basic mathematical equation given in Eq. 1 [15] is used to estimate an overall uncertainty. This equation is designed to combine uncertainties from multiple variables, to provide an accurate measurement of overall uncertainty. It was used to calculate uncertainty in $K$-factor. The uncertainty in $K$-factor comprised the uncertainties of the flowmeter and pressure-drop transducer.

$$
\Delta R=\left\{\sum_{i=1}^{N}\left(\frac{\partial R}{\partial X_{i}} \Delta X_{i}\right)^{2}\right\}^{\frac{1}{2}}
$$

Where $\triangle R$ is an absolute uncertainty in quantity $R$ which depends on $X_{1}, X_{2} \ldots . X_{N}$ with the known uncertainties $\Delta X_{1}$, $\triangle X_{2} \ldots \Delta X_{N}$.

The procedure to calculate the $K$ - factor uncertainty across the valve is discussed below:

$$
\begin{gathered}
K=\frac{2 P_{\text {drop }} \rho}{G^{2}} \\
\Delta K= \pm \sqrt{\left(\frac{\partial K}{\partial P_{d r o p}}\right)^{2}\left(\Delta P_{d r o p}\right)^{2}+\left(\frac{\partial K}{\partial G}\right)^{2}(\Delta G)^{2}} \\
\Delta K= \pm \sqrt{\left(\frac{2 \rho}{G^{2}}\right)^{2}\left(\Delta P_{d r o p}\right)^{2}+\left(\frac{-4 P_{d r o p} \rho}{G^{3}}\right)^{2}(\triangle G)^{2}}
\end{gathered}
$$

Where $\triangle K$ is $K$-factor absolute uncertainty, $G$ is mass flux $\left(\mathrm{kg} \mathrm{s}^{-1} \mathrm{~m}^{-2}\right), P_{\text {drop }}$ is pressure-drop $\left(\mathrm{N} \mathrm{m}^{-2}\right), \rho$ is density $(\mathrm{kg}$ $\left.\mathrm{m}^{-3}\right), \triangle G$ is known uncertainty in mass flux, and $\triangle P_{\text {drop }}$ is known uncertainty in pressure-drop.

$\%$ value is obtained by using the formula in Eq. 5:

$$
\% \text { Value }=\frac{\triangle K}{K_{\text {actual }}} * 100
$$

The $K$-factor uncertainty for all cases at channel inlet and outlet came to be $\pm 7.21 \%$ approximately. A sample calculation for case 1 for channel 1 is shown below:

At channel 1 inlet: $\rho=932.97 \mathrm{~kg} \mathrm{~m}^{-3}, G=207.99 \mathrm{~kg} \mathrm{~s}^{-1} \mathrm{~m}^{-2}, P_{\text {drop }}=27.83 \mathrm{~N} \mathrm{~m}^{-2}, \triangle G=6.24, \triangle P_{\text {drop }}=1.113, K_{\text {actual }}=1.2$

$$
\begin{aligned}
\triangle K & = \pm 0.08653 \\
\% \text { Value } & =\frac{0.08653}{1.2} * 100= \pm 7.21 \%
\end{aligned}
$$

At channel 1 outlet: $\rho=310.35 \mathrm{~kg} \cdot \mathrm{m}^{-3}, G=207.99 \mathrm{~kg} \cdot \mathrm{s}^{-1} \cdot \mathrm{m}^{-2}, P_{\text {drop }}=223.03 \mathrm{~N} \cdot \mathrm{m}^{-2}, \triangle G=6.23, \triangle P_{\text {drop }}=8.92, K_{\text {actual }}=$

$$
\triangle K= \pm 0.2308
$$




$$
\% \text { Value }=\frac{0.2308}{3.2} * 100= \pm 7.21 \%
$$

The uncertainties related to the system pressure, inlet temperature and mass flow rate are single-valued; therefore, comprise instrumental uncertainties only, which are $0.5 \%, 0.5 \%$, and $3.0 \%$ respectively. The overall uncertainty in flow instability boundary comprises the combinations of all the uncertainties related to $K$-factor, system pressure, inlet temperature and mass flow rate. This yields an estimation of $\pm 11.21 \%$ uncertainty in flow instability boundary.

$$
=7.21 \%+0.5 \%+0.5 \%+3.0 \%=11.21 \%
$$

It can be concluded that the presented flow instability boundary results are estimated to be accurate within $\pm 11.21 \%$ of uncertainty value. It is expected that if any researcher performs the numerical simulation on the presented experiment data, the maximum error difference $\pm 11.21 \%$ will be expected between the experimental flow instability boundary power and the numerical flow instability boundary power, if the sufficiently accurate numerical model for prediction is used.

\subsection{Period of Oscillation}

An accurate way to determine the oscillation period is to do a Fast Fourier Transformation (FFT) of the flow meter data at the instability boundary. This was done for all the seven experimental cases. For Case 1, Figs. 6 and 7 show the amplitude plot of FFT for channels 1 and 2. It gave only a major oscillation period of $7.8 \mathrm{sec}$. The oscillation period was calculated by taking the inverse of the frequency. The phase between the oscillations was checked by plotting the phase shift plot of the FFT, shown in Fig. 8. It is evident from Figs. 6, 7 and 8 that at the frequency corresponding to the maximum amplitude, where the phase crosses over, indicating out-of-phase.

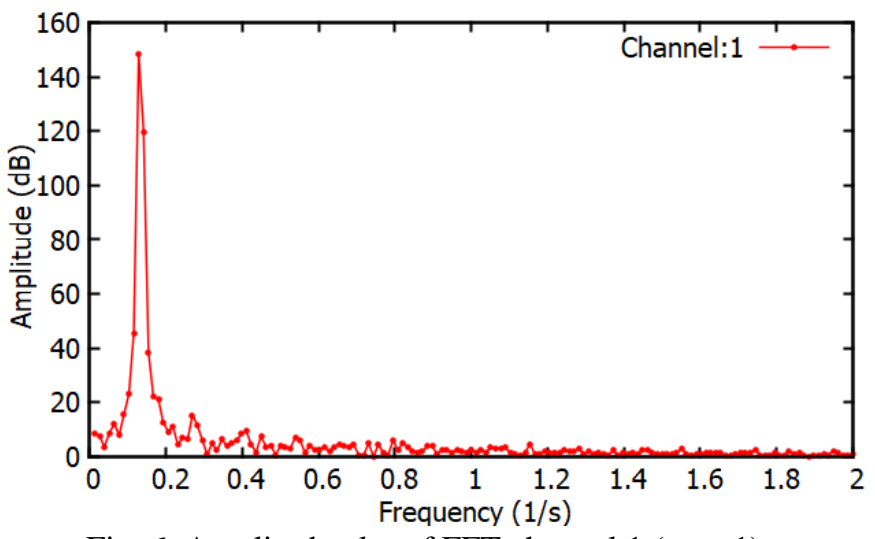

Fig. 6. Amplitude plot of FFT channel 1 (case 1).

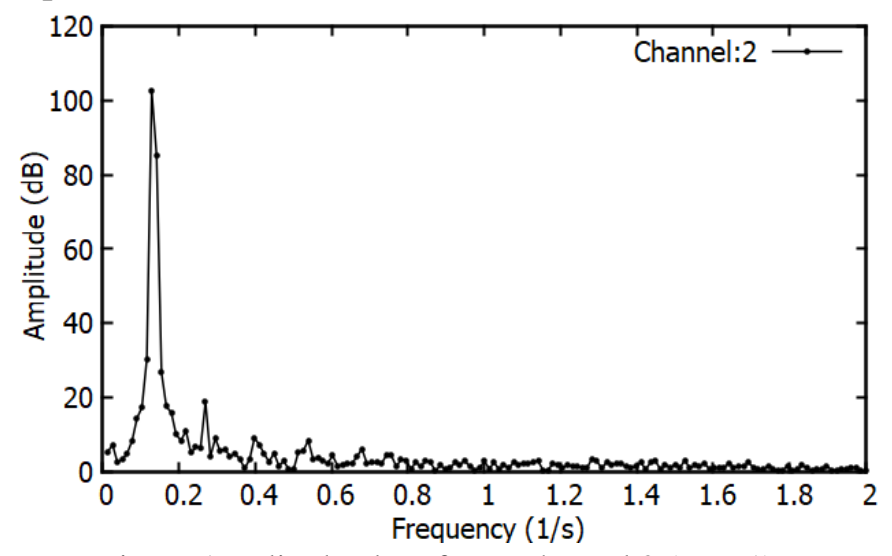

Fig. 7. Amplitude plot of FFT channel 2 (case 1).

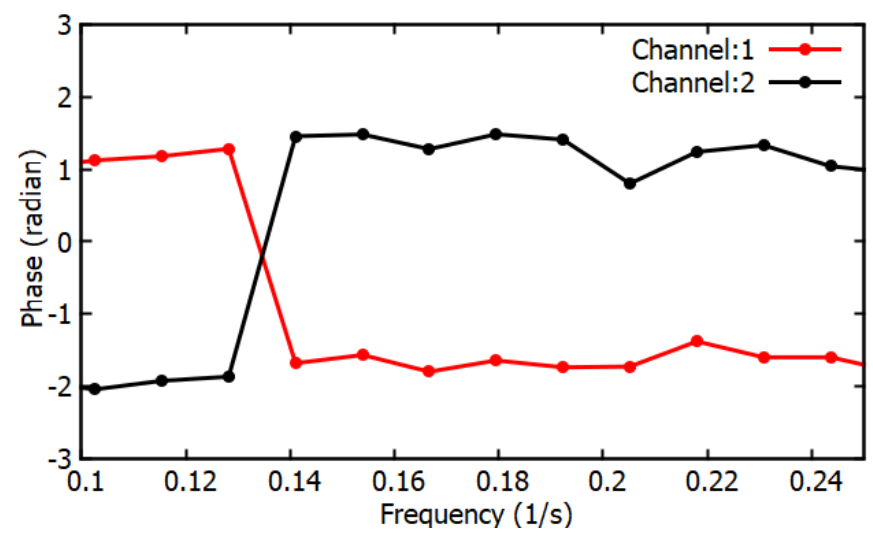

Fig. 8. Phase plot of FFT (case1). 


\section{Conclusion}

a) Supercritical mass flow instability was determined experimentally for seven cases using $\mathrm{CO}_{2}$. The data at the onset of mass flow instability boundary was presented for all the cases. This data would be useful for those who wish to validate the licensed software's or in-house programs in order to make the software or program sufficiently accurate for engineering use.

b) The experimental facility used for experiments was described.

c) The mass flow rate distribution in channels with input power increase was discussed. Initially, at low input power, the mass flow rate between the channels was symmetric. With increase in input power, it redistributed between the channels and became asymmetric. With further input power increase, the mass flow rate started oscillating $180^{\circ}$ out-of-phase, and flow instability boundary was determined.

d) The estimation of uncertainty related to flow instability boundary was discussed.

e) Fast Fourier Transformation was used to determine the oscillation period of each case.

\section{Acknowledgment}

The financial support received from CNL in building up the loop and the University of Manitoba is gratefully acknowledged. Friendly help received from Anantvir Singh Saini and Dhanashree Ghadge is highly appreciated.

\section{References}

[1] Zuber N."An analysis of thermally induced flow oscillations near critical and super-critical region." report by marshall space flight center nasa huntsville, May 1966.

[2] J. Zhao, P. Saha, and M. S. Kazimi, "Hot-Channel Stability of Supercritical Water-Cooled Reactors-I: Steady-State and Sliding Pressure Startup," Nucl. Technol., vol. 158, no. 2, pp. 158-173, May 2007, doi: 10.13182/NT07-A3833.

[3] W. Ambrosini, "On the analogies in the dynamic behaviour of heated channels with boiling and supercritical fluids," Nucl. Eng. Des., vol. 237, no. 11, pp. 1164-1174, Jun. 2007, doi: 10.1016/j.nucengdes.2007.01.006.

[4] V. Chatoorgoon, "Non-dimensional parameters for static instability in supercritical heated channels," Int. J. Heat Mass Transf., vol. 64, pp. 145-154, Sep. 2013, doi: 10.1016/j.ijheatmasstransfer.2013.04.026.

[5] Y. Su, J. Feng, W. Tian, S. Qiu, and G. Su, "Theoretical Study on the Flow Instability of Supercritical Water in the Parallel Channels," p. 8, 2012.

[6] T. Xiong, X. Yan, Z. Xiao, Y. Li, Y. Huang, and J. Yu, "Experimental study on flow instability in parallel channels with supercritical water," Ann. Nucl. Energy, vol. 48, pp. 60-67, Oct. 2012, doi: 10.1016/j.anucene.2012.05.018.

[7] X. Xi, Z. Xiao, X. Yan, Y. Li, and Y. Huang, "An experimental investigation of flow instability between two heated parallel channels with supercritical water," Nucl. Eng. Des., vol. 278, pp. 171-181, Oct. 2014, doi: 10.1016/j.nucengdes.2014.06.034.

[8] E. Shitsi, S. K. Debrah, V. Y. Agbodemegbe, and E. Ampomah-Amoako, "Investigation of flow instability using axially decreased power shape in parallel channels with water at supercritical pressure," Ann. Nucl. Energy, vol. 116, pp. 152-162, Jun. 2018, doi: 10.1016/j.anucene.2018.02.035.

[9] A. S. Saini, V. Chatoorgoon, and D. S. Ghadge, "Experimental investigation of flow instability between two vertical parallel channels using supercritical CO2,"J. Nucl. Eng. Radiat. Sci., NERS-19-1088, July 2020, https://doi.org/10.1115/1.4047716.

[10] S. K. Debrah, W. Ambrosini, and Y. Chen, "Assessment of a new model for the linear and nonlinear stability analysis of natural circulation loops with supercritical fluids," Ann. Nucl. Energy, vol. 58, pp. 272-285, Aug. 2013, doi: 10.1016/j.anucene.2013.03.033.

[11] M. Sharma, K. Bodkha, D. S. Pilkhwal, and P. K. Vijayan, "A Supercritical Pressure Parallel Channel Natural Circulation Loop," p. 17, 2015. 
[12] J. Liu, H. Li, X. Lei, K. Guo, and L. Li, "Numerical study on the effect of pipe wall heat storage on density wave instability of supercritical water," Nucl. Eng. Des., vol. 335, pp. 106-115, Aug. 2018, doi: 10.1016/j.nucengdes.2018.04.024.

[13] D. S. Ghadge, V. Chatoorgoon, and S. J. Ormiston, "The effect of heat storage on supercritical flow stability in two heated parallel channels," Int. J. Heat Mass Transf., vol. 153, p. 119599, Jun. 2020, doi: 10.1016/j.ijheatmasstransfer.2020.119599.

[14] E. Shitsi, S. K. Debrah, V. Y. Agbodemegbe, and E. Ampomah-Amoako, "Flow Instability in Parallel Channels with Water at Supercritical Pressure: A Review," World J. Eng. Technol., vol. 06, no. 01, pp. 128-160, 2018, doi: 10.4236/wjet.2018.61008.

[15] R. J. Moffat, "Describing the uncertainties in experimental results," Exp. Therm. Fluid Sci., vol. 1, no. 1, pp. 3-17, Jan. 1988, doi: 10.1016/0894-1777(88)90043-X. 